\title{
Moral perception, educational environment, and development of medical professionalism in medical students during the clinical rotations in Peru
}

\author{
Montserrat San-Martín ${ }^{1}$ - Edgar M. Rivera ${ }^{2}$. \\ Adelina Alcorta-Garza ${ }^{3} \cdot$ Luis Vivanco $^{4,5}$ (D)
}

Published online: 7 March 2016

(C) The Author(s) 2016. This article is published with open access at Springerlink.com

\begin{abstract}
The aim of this study was to determine the relationship between a clinical environment and the development of empathy, teamwork, and lifelong learning in medical students who are doing their first clinical rotation. The Jefferson Scales of Empathy (JSE), Jefferson Scale of Attitudes toward Physician-Nurse Collaboration (JSAPNC), and Jefferson Scale of Physician Lifelong Learning (JeffSPLLL) were administered to 60 sixth-year medical students, before and after their first clinical rotation in five health care institutions. The Dundee Ready Education Environment Measure questionnaire (DREEM) was administered to measure their perception of the educational environment after the rotation was finished. Scores were compared to determine differences before and after the rotation. Other variables associated with gender, age, and moral perception, were included into the comparisons. A correlation analysis was also performed. The analyses confirmed a positive association among the measured elements of medical professionalism. Lifelong learning decreased $(p=0.03)$ after the rotation. Associations were found between the educational environment and the development of lifelong learning $(P=+0.29 ; p=0.03)$; and between the
\end{abstract}

Luis Vivanco

lvivanco@riojasalud.es

1 Scientific Computing Group (GRUCACI), University of La Rioja, Logroño, Spain

2 Faculty of Medicine, National University San Agustin, Arequipa, Peru

3 University Autonomous of Nuevo Leon, Monterrey, Spain

4 Platform of Bioethics and Medical Education, Center for Biomedical Research of La Rioja (CIBIR), St. Piqueras 98, 26006 Logroño, Spain

5 Area of Health, Nutrition and Bioethics, Iberoamerican University Foundation (FUNIBER), Barcelona, Spain 
development of attitudes toward teamwork and the educational environment $(P=+$ $0.29 ; p=0.03$ ). During the rotational internship, the development of some components of professionalism in medical students is influenced by the clinical environment. Gender, age, and moral perception influence the development of some elements of medical professionalism and the perception of the educational environment.

Keywords Empathy Physician-Nurse relations - Undergraduate medical education · Moral perception $\cdot$ Faculty $\cdot$ Peru

\section{Introduction}

Ethics and medicine are two fields of knowledge that have been closely related since their origins. In fact, when it comes to medicine, professionalism requires, in addition to technical knowledge, the exercise of necessary ethical conduct (DeAngelis 2015; Vivanco and Delgado-Bolton 2015). In the field of medical education, the acquisition of this ethical conduct, in the medical student as in the doctor in training, is not only attributed to the learning and follow up of a professional code, but primarily to a style of learning that comes by contact with the professor in a clinical and hospitable environment (Eckles et al. 2005). As such, it is not so surprising that health care institutions play an important role in a doctor's ethical training.

In Latin America, the participation of health care institutions in medical education programs have been included at the regional level since the beginnings of the 70's (Andrade 1978). These institutions acquire a more proactive role in medical education from the third year of the career. However, it is during the last year, also called Medical Rotating Internship, in which they have a major and almost exclusive role. The students complete their training during the last year by rotating through some of the services offered by the hospital. These services are usually consistent with the branch areas of the profession, such as: pediatrics, internal medicine, surgery, and obstetrics and gynecology. This training model is not exclusive to Latin America. The period of clinical rotation is a teaching model widely disseminated in medical education at the international level. There is in fact a large volume of literature on the role that clinical experience has in the acquisition of new types of knowledge (Daelmans et al. 2004) on professional skills (van Mook et al. 2009) or in the relationship between students and teachers (Pitkala and Mantyranta 2003). Recent studies have warned about the challenges and difficulties that this model poses to health care institutions, which are forced to know how to combine professional responsibility toward the patient, with the responsibility of teaching the student (Duvivier et al. 2014). In countries such as Peru, where public hospitals have insufficient resources to respond to the social demands (Herrera-Añazco et al. 2015a), teachers are confronted with important difficulties and challenges to adequately respond to the training needs of the students and the doctors in training (Herrera-Añazco et al. 2015b).

The first objective of this study was to measure the effect that the first clinical rotation has on the development of empathy, the skills of inter-professional collaborative work, and lifelong medical learning in the medical student of a university of Peru. The second objective was to discover if this effect varied with age and gender. The third objective was to determine the effect that the moral perception has on the development 
of any of the four measured elements: empathy, team work, learning, and the perception of the educational environment during the clinical rotation. Finally, the fourth objective was to determine the existence of an association between the development of empathy, team work, and lifelong learning; as well as the relationship that exists between their development and the perception of the educational environment offered by the clinical rotation.

\section{Methods}

\section{Participants}

The study was developed in 2014 and counted with the participation of sixth year medical students from the San Augustine National University (Arequipa, Peru) who at that time were about to perform the first of the four clinical rotations that consists of the medical internship rotation year. This rotation was conducted in the services of internal medicine, obstetrics and gynecology, general surgery, and pediatrics at five hospitals in Arequipa.

\section{Design}

After having the approval of the Faculty of Medicine from the National University of San Agustin, and before the start of the first clinical rotation, all sixth year medical students received a general informative discussion of the study. Students interested in participating received a sealed envelope that included: i) a fact sheet; ii) a group of three questionnaires designed to measure the medical empathy and team work between the doctor and the nurse, and lifelong medical learning; iii) a brief socio-demographic form where every student included an alphanumeric pseudonym that anonymously identified their questionnaires; and iv) a second sealed envelope that was used to return the questionnaires and the form once these were answered. Three months later, and during the week after the end of the first rotation, a similar activity was developed where a second envelope was distributed in which, in addition to the three previously administered questionnaires, it also included a questionnaire to measure the perception of the educational environment during the rotation that had taken place.

\section{Instruments}

The study used the Jefferson Scale of Empathy (JSE), the student version (JSE-S), to measure students' orientation toward empathetic relationships with patients (Hojat 2006). A sample item is: "Physicians should try to stand in their patient's shoes when providing care to them". A higher score means that the student has more of an orientation or behavioral tendency toward empathic engagement in patient care (Hojat et al. 2002). The JSE-S has 20 Likert scale-type items of 7 points (1:strongly disagree; 7:strongly agree).

The Jefferson Scale of Attitudes Toward Physician-Nurse Collaboration (JSAPNC) to measure a positive attitude toward collaborative work in inter-professional health care teams (Hojat et al. 1999). The physician-nurse collaboration that is measured by the JSAPNC is defined as an ability of nurses and physicians for working together 
cooperatively, sharing responsibilities for solving problems and making decisions to formulate and carry out plans for patient care (Baggs and Schmitt 1988). The JSAPNC has 15 Likert scale-type items of 4 points (1:strongly disagree; 4:strongly agree).

The Jefferson Scale of Physician Lifelong Learning (JeffSPLL) to measure the development of skills oriented at information search, the use of learning opportunities, and self-motivation (Wetzel et al. 2010). The JeffSPLL has 14 Likert scale-type items of 4 points (1:strongly disagree; 4:strongly agree).

The Dundee Ready Education Environment Measure (DREEM) to measure the perception that students have on the educational environment offered at the center (Roff et al. 1997). The DREEM has 50 Likert scale-type items of 5 points (0:strongly disagree; 4:strongly agree). The DREEM includes five domains of perception: learning, teachers, environment in the center, and the student's academic and social perception.

\section{Other variables of interest}

Information on the age and gender were collected in the forms accompanying the questionnaire. At the end of the clinical rotation, students were also asked if during the clinical experience, they had witnessed professional behaviors that they might consider morally inadequate in the management of information, the use of medications, or in the treatment of patients.

\section{Statistical analysis}

The reliability of the instruments that were used was measured by Cronbach's alpha coefficient in the questionnaires administered before and after the rotation. Once the normality was studied, a comparative analysis on the basis of sex was carried out for each instrument during the two moments in which they were administered. The same was done at the end of the study for the case of the variables associated with the skills to identify morally inadequate professional behaviors. Lastly, an analysis was made on the temporal evolution in the development of empathy, team work, and lifelong learning in order to determine the existence of changes that were statistically significant. A correlation analysis was used to determine the association between the four elements measured, and between age and each one of them. The data processing was carried out with the R software (R Team 2014), version 3.1.1 for Windows, and included the use of nortest (Gross 2012) and multilevel (Bliese 2013) statistical packages.

\section{Results}

60 of the 100 students, who were studying in sixth year medicine, agreed to participate in the study and returned both questionnaires answered. From this group, 32 (53\%) were male and $28(47 \%)$ were women. The mean age of the group was 25 years, ranging from 22 to 33 years $(\mathrm{SD}=2)$.

The four instruments showed adequate psychometric properties, values given by Cronbach's alpha coefficient close to or higher than 0.70 before rotation, and higher than 0.70 in all cases at the end of it. The summary of the descriptive analysis for the overall sample is shown in Table 1. 
Table 1 Descriptive analysis and psychometric properties of the scales, before and after the first clinical rotation, in 60 students of medicine from a Peruvian University

\begin{tabular}{|c|c|c|c|c|c|c|c|}
\hline \multirow[t]{2}{*}{ Statisticals } & \multicolumn{3}{|l|}{ Before } & \multicolumn{4}{|l|}{ After } \\
\hline & JSE & JSAPNC & JeffSPLL & JSE & JSAPNC & JeffSPLL & DREEM \\
\hline Possible range & $20-140$ & $15-60$ & $14-56$ & $20-140$ & $15-60$ & $14-56$ & $0-200$ \\
\hline Actual range & $86-135$ & $29-60$ & $38-56$ & $73-140$ & $30-58$ & $29-56$ & $45-176$ \\
\hline Mean & 112 & 46 & 47 & 109 & 46 & 45 & 124 \\
\hline Standard deviation & 11 & 8 & 4 & 14 & 6 & 5 & 24 \\
\hline \multicolumn{8}{|l|}{ Quartile } \\
\hline $1 \mathrm{st}$ & 105 & 41 & 45 & 104 & 42 & 43 & 111 \\
\hline 2nd (Median) & 113 & 47 & 47 & 110 & 45 & 46 & 127 \\
\hline 3 th & 119 & 51 & 49 & 117 & 49 & 49 & 139 \\
\hline Alpha coefficient & 0.68 & 0.84 & 0.69 & 0.82 & 0.79 & 0.81 & 0.93 \\
\hline
\end{tabular}

JSE Jefferson Scale of Empathy

JSAPNC Jefferson Scale of Attitudes Toward Physician-Nurse Collaboration

JeffSPLL Jefferson Scale of Physician Lifelong Learning

DREEM Dundee Ready Education Environment Measure

Scores observed at the start of the rotation, in the case of empathy and lifelong medical learning, were slightly higher than those observed at the end (Table 1). However, we could only accept that this decline was statistically significant $(p=0.03)$ only when it came to the case of learning. The comparative analysis, both the beginning and the end of the rotation, did not show the existence of statistically significant differences in any of the four questionnaires used in function of the sex. There was no statistical association between age and the development of the four elements measured.

Students with a low moral perception, defined as the ability to identify behaviors with a particular moral burden, showed less development of inter-professional collaborative work skills $(p=0.04)$. At a $p<0.10$ level of significance, we can accept that these students give a less critical score with respect to the educational environment of the service where they conducted their first clinical experience (Table 2).

Correlation analysis (Table 3 ) confirmed the existence of an association between the development of empathy and teamwork $(r=+0.37 ; p<0.001)$, and between empathy and the development of skills in lifelong learning $(r=+0.31 ; p<0.05)$. The analysis also showed that the overall perception of the educational atmosphere is positively related to further development of the skills in lifelong learning $(r=+0.29 ; p<0.05)$. A similar situation is observed in the case of teamwork $(r=+0.29 ; p<0.05)$, which is associated in this case with the student's perception of the teachers and the environment of the service $(r=+0.29 ; p<0.05)$.

\section{Discussion}

The questionnaires showed adequate psychometric properties, with Cronbach's alpha coefficient close to or above 0.70. Except in the case of JSAPNC, the increase in the 
Table 2 Association among the students' moral perception of professionals' misconduct during the clinical rotation and empathy, teamwork, lifelong learning and perception of the educational environment $(N=60)$

\begin{tabular}{|c|c|c|c|c|c|}
\hline Students' moral perception & $N$ & $\begin{array}{l}\text { JSE } \\
\mathrm{M}(\mathrm{SD})\end{array}$ & $\begin{array}{l}\text { JSAPNC } \\
\text { M (SD) }\end{array}$ & $\begin{array}{l}\text { JeffSPLL } \\
\text { M (SD) }\end{array}$ & $\begin{array}{l}\text { DREEM } \\
\text { M (SD) }\end{array}$ \\
\hline \multicolumn{6}{|l|}{ Global perception ${ }^{\mathrm{a}}$} \\
\hline Yes & 56 & 109 (14) & $46(6)^{\dagger}$ & $45(5)$ & $123(24)^{\dagger}$ \\
\hline Never & 4 & $107(9)$ & $41(4)$ & $49(5)$ & $138(7)$ \\
\hline \multicolumn{6}{|l|}{ Misuse of information ${ }^{\mathrm{b}}$} \\
\hline Yes & 53 & $109(14)$ & $46(6) *$ & $45(5)$ & $123(25)$ \\
\hline Never & 7 & $107(7)$ & $42(4)$ & $46(5)$ & $133(9)$ \\
\hline \multicolumn{6}{|l|}{ Misconduct toward patients ${ }^{\mathrm{c}}$} \\
\hline Yes & 55 & $109(14)$ & $46(6)^{\dagger}$ & $45(5)$ & $123(24)$ \\
\hline Never & 5 & $103(11)$ & $41(3)$ & $47(6)$ & $135(10)$ \\
\hline \multicolumn{6}{|l|}{ Misuse of medications ${ }^{\mathrm{d}}$} \\
\hline Yes & 43 & $108(13)$ & $46(6)$ & $45(5)$ & $121(25)$ \\
\hline Never & 17 & $111(15)$ & $45(6)$ & $46(6)$ & $131(19)$ \\
\hline
\end{tabular}

$J S E$ Jefferson Scale of Empathy

JSAPNC Jefferson Scale of Attitudes Toward Physician-Nurse Collaboration

JeffSPLL Jefferson Scale of Physician Lifelong Learning

DREEM Dundee Ready Education Environment Measure

N: participants; $M$ mean; $S D$ standard deviation

${ }^{\text {a }}$ During the rotation, the student saw at least one of these episodes: misuse of information, misconduct toward patients, or misuse of medications

${ }^{b}$ During the rotation, the student saw at least an episode related with a misuse of patient information

${ }^{\mathrm{c}}$ During the rotation, the student saw at least an episode related with a misconduct toward to the patient

${ }^{\mathrm{d}}$ During the rotation, the student saw at least an episode related with a misuse of medication

${ }^{\dagger} p<0.1 ; * p<0.05 ; * * p<0.01 ; * * * p<0.001$

value of these coefficients is indicative of an improvement in the understanding of the measured item. This coincides with the kind of knowledge that the student is expected to acquire from the clinical experience (Stern 2006).

The first objective of this study was to measure the effect that the first clinical rotation has on the development of empathy, the skills of interprofessional collaborative work, and lifelong medical learning. The decrease observed in the questionnaire scores for empathy and confirmed in the case of lifelong learning can be indicative of a deterioration in the development of both elements as a result of this first experience. This fact, if it coincides with the results described in previous studies of students who perform their first clinical experience (Lempp and Seale 2004), requires a more in-depth and long term analysis, since it can also be a side effect of an adjustment process that the student experiences as a result of the change in the pre-clinical learning environment, to an entirely clinical one (Arnold 2007). The fact that the decline was statistically significant only in the case of the skills for lifelong learning, and not in the other two, seems to point in the latter's direction. 
Table 3 Correlation among empathy, attitude toward physician-nurse collaboration, lifelong learning, educational environment, and age in Peruvian medical students attending their first clinical rotation $(N=60)$

\begin{tabular}{lllll}
\hline Surveys & Age & JSE & JSAPNC & JeffSPLL \\
\hline JSE & +0.05 & 1 & & \\
JSAPNC & -0.04 & $+0.37 * * *$ & 1 & \\
JeffSPLL & +0.06 & $+0.31^{*}$ & +0.24 & 1 \\
DREEM & -0.16 & +0.03 & $+0.29 *$ & $+0.29 *$ \\
Perception of teaching & -0.18 & +0.19 & +0.24 & +0.19 \\
Perception of teachers & -0.16 & +0.13 & $+0.29 *$ & +0.21 \\
Academic self-perception & -0.12 & +0.00 & +0.21 & +0.03 \\
Perception of the environment & -0.15 & +0.13 & $+0.29 *$ & +0.21 \\
Social self-perception & -0.06 & +0.00 & +0.21 & +0.03 \\
\hline
\end{tabular}

$J S E$ Jefferson Scale of Empathy

JSAPNC Jefferson Scale of Attitudes Toward Physician-Nurse Collaboration

JeffSPLL Jefferson Scale of Physician Lifelong Learning

DREEM Dundee Ready Education Environment Measure

${ }^{*} p<0.05 ; * * p<0.01 ; * * * p<0.001$

The second objective of this study was to determine if the development of the measured elements varied depending on the gender or age, in the sample that was studied. Previous studies with medical students in different cultural contexts concur with the indication of the existence of an empathic orientation that is slightly higher in women (Tavakol et al. 2011; Leombruni et al. 2014; Alcorta-Garza et al. 2005; Wen et al. 2013; Shariat and Habibi 2013). A similar situation has been described in medical students in the case of skills for inter-professional collaborative work (Hojat et al. 1999). Such differences disappear in the case of perception for the educational environment (Palés et al. 2015) and the skills for lifelong medical learning (Wetzel et al. 2010). Differences in the development of these elements as a function of age in studies with students have not been described either, although they have been described in studies with professionals that include a wider range of age (Hojat 2006). In the studied sample, no association was found between the development of the measured elements, and the gender or age. Which, save for the JSE and JSAPNC case, coincides with the results observed in previous studies. In the studied sample, the slight difference in the scores for JSE and JSAPNC between the group of men and women did not reach statistical significance, possibly as a result of the effect that the dispersion has on the small sample size, rather than the singularity of another type.

Two works of recent publication warned of the work overload, stress, and the social demand not covered in the public hospitals of Peru (Herrera-Añazco et al. 2015b), and the consequences that such a situation has on the training of physicians-in-training and medical students in the case of teaching hospitals, (Herrera-Añazco et al. 2015b). In both jobs, some of the hospitals where the students in this study underwent their clinical rotations, were included. As a result, we hope that in the 3 months of living with the health care teams of these centers, students have been able to witness ethically complex situations, either in the treatment of patients, in the use of information and inter- 
professional cooperation, or in the administration and prescription of medications. With this as a premise, the third objective of this study was to determine the effect that the moral perception of the student has on the development of any of the measured elements. Based on emerging research, some authors propose that human perception is preferentially attuned to moral content (Gantman and Van Bavel 2015). According to them, moral concerns enhance the detection of morally relevant stimuli, and both command and direct attention. These perceptual processes, in turn, have important consequences for moral judgment and behavior (Gray et al. 2012). The differences observed, both in the scores of the skills for collaborative inter-professional work, as in the assessment of the educational environment of the first clinical rotation, concurs with this idea. A greater moral perception favors, in the case of the studied sample, the student to acquire further development of skills oriented to medical professionalism, and in the same sense, to develop more critical thinking with regard to the educational environment that the service offers.

In relation to the fourth objective of this study, the positive correlations observed between the measured elements of medical professionalism confirm, in practice, the role that is attributed to them as structural components of medical professionalism (Stern 2006). In addition, the results confirm the important role that the clinical environment has in the process of learning and development of these skills, in the case of the educational environment (Mueller 2009). In the case of inter-professional collaborative work skills between the doctor and the nurse, the study demonstrates the important role that the educator's conduct and the dynamics of the service itself have for the professional development of the student. Another interpretation deserves the association found between the development of lifelong learning and the perception of the educational environment. The observed relationship can be explained both in the sense that certain clinical environments offer favorable conditions for the development of this ability (Mueller 2009), as well as in the sense that students with a greater development of this ability can optimize the learning opportunities offered to them by the hospital (Sternberg 1985).

In conclusion, the study confirms the usefulness of psychometric instruments used for the measurement of professional skills and for the evaluation of results in the learning process, in this case, viewed from the perspective of the medical professionalism. The study's main limitation is most likely that it only explores the immediate effect that the first clinical experience has in the development of the measured elements. We need a long-term follow-up that allows us to determine whether the observations change over time. In spite of this, the study provides information of great interest for both educators and managers of medical training and health care programs.

Acknowledgments The authors would like to thank the International University Foundation (FUNIBER) in Peru for the facilities they offered during this study. The authors would also like to give special thanks to Marcel Colet and Jorge Daniel, responsible for the translation process of this study.

\section{Compliance with ethical standards}

Funding This study was supported by the Fundacion Rioja Salud (FRS).

Conflict of interest The authors certify that they had no conflict of interest for this study. 
Open Access This article is distributed under the terms of the Creative Commons Attribution 4.0 International License (http://creativecommons.org/licenses/by/4.0/), which permits unrestricted use, distribution, and reproduction in any medium, provided you give appropriate credit to the original author(s) and the source, provide a link to the Creative Commons license, and indicate if changes were made.

\section{References}

Alcorta-Garza, Adelina, Juan González-Guerrero, Silvia Tavitas-Herrera, Francisco Rodríguez Lara, and Mohammadreza Hojat. 2005. Validity and reliability of the Jefferson Scale of Physician Empathy in Mexican medial students. Salud Mental 28: 57-63.

Andrade, Jorge. 1978. Marco conceptual de la educación médica en América Latina. Educación Médica y Salud 12: 1-19.

Arnold, Robert. 2007. Formal, informal, and hidden curriculum in the clinical years: where is the problem? Journal of Palliative Medicine 10: 646-648.

Baggs, Judith G., and Madeline H. Schmitt. 1988. Collaboration between nurses and physicians. Journal of Nursing Scholarship 20: 145-149.

Bliese, Paul. 2013. Multilevel Functions. R package version 2.5. http://CRAN.R-project.org/package=multilevel. Accessed 15 Oct 2015.

Daelmans, H.E.M., R.J.I. Hoogenboom, A.J.M. Donker, A.J.J.A. Scherpbier, C.D.A. Stehouwer, and C.P.M. Van der Vleuten. 2004. Effectiveness of clinical rotations as a learning environment for achieving competences. Medical Teacher 26: 305-312.

DeAngelis, Catherine. 2015. Medical professionalism. JAMA 313: 1837-1838.

Duvivier, Robbert, Renée Stalmeijer, Jan van Dalen, Cees van der Vleuten, and Albert Scherpbier. 2014. Influence of the workplace on learning physical examination skills. BMC Medical Education 14: 61.

Eckles, Rachael E., Eric M. Meslin, Margaret Gaffney, and Paul R. Helft. 2005. Medical ethics education: where are we? Where should we be going? A review. Academic Medicine 80: 1143-1152.

Gantman, Ana, and Jay J. Van Bavel. 2015. Moral perception. Trends in Cognitive Sciences 19: 631-633.

Gray, Kurt, Liane Young, and Adam Waytz. 2012. Mind perception is the essence of morality. Psychological Inquiry 23: 101-124.

Gross, Juergen. 2012. nortest: Tests for Normality. R package version 1.0-2.

Herrera-Añazco, Percy, Luis Bonilla-Vargas, Adrian V. Hernandez, and Manuela Silveira-Chau. 2015a. Perception of physicians about medical education received during their Nephrology residency training in Peru. Jornal Brasileiro de Nefrologia 37: 333-340.

Herrera-Añazco, Percy, Vicente Benites-Zapata, Adrian V. Hernandez, Edward Mezones-Holguin, and Manuela Silveira-Chau. 2015b. Mortality in patients with chronic kidney disease undergoing hemodialysis in a public hospital of Peru. Jornal Brasileiro de Nefrologia 37: 192-197.

Hojat, Mohammadreza. 2006. Empathy in patient care: antecedents, development, measurement, and outcomes. New York: Springer.

Hojat, Mohammadreza, Sylvia K. Fields, J. Jon Veloski, Margaret Griffiths, Mitchell J.M. Cohen, and James D. Plumb. 1999. Psychometric properties of an attitude scale measuring physician-nurse collaboration. Evaluation \& the Health Professions 22: 208-220.

Hojat, Mohammadreza, Joseph Gonnella, Salvatore Mangione, Thomas Nasca, Jon Veloski, Jon Erdmann, Clara Callahan, and Mike Magee. 2002. Empathy in medical students as related to academic performance, clinical competence and gender. Medical Education 36: 522-527.

Lempp, Heidi, and Clive Seale. 2004. The hidden curriculum in undergraduate medical education: qualitative study of medical students' perceptions of teaching. British Medical Journal 329: 770-773.

Leombruni, Paolo, Mariangela Di Lillo, Marco Miniotti, Angelo Picardi, Guido Alessandri, Chiara Sica, Francesca Zizzi, Lorys Castelli, and Riccardo Torta. 2014. Measurement properties and confirmatory factor analysis of the Jefferson Scale of Empathy in Italian medical students. Perspectives on Medical Education 3: 419-430.

Mueller, Paul. 2009. Incorporating professionalism into medical education: the Mayo Clinic experience. Keio Journal of Medicine 58: 133-143.

Palés, Jorge, Arcadi Gual, Jesus Escaneroi, Inmaculada Tomás, Felipe Rodríguez de Castro, Elorudy Marta, Virumbrales Montserrat, Rodríguez Gerardo, and Arce Víctor. 2015. Educational climate perception by 
preclinical and clinical medical students in five Spanish medical schools. International Journal of Medical Education 6: 65-75.

Pitkala, K.H., and T. Mantyranta. 2003. Professional socialization revised: medical students' own conceptions related to adoption of the future physician's role-a qualitative study. Medical Teacher 25: 155-160.

R Team. R. 2014. A language and environment for statistical computing. Vienna: R Foundation for Statistical Computing. http://www.R-project.org/. Accessed 15 Oct 2015.

Roff, Sue, Sean McAleer, Ronald M. Harden, Mona Al-Qahtani, Ashraf Uddin Ahmed, Horacio Deza, Guido Groenen, and Praorn Primparyon. 1997. Development and validation of the Dundee ready education environment measure (DREEM). Medical Teacher 19: 295-299.

Shariat, Seyed Vahid, and Mojtaba Habibi. 2013. Empathy in Iranian medical students: measurement model of the Jefferson Scale of Empathy. Medical Teacher 35: e913-e918.

Stern, David T. 2006. Measuring medical professionalism. New York: Oxford University Press.

Sternberg, Robert. 1985. Beyond IQ: a triarchic theory of human intelligence. Cambridge: Cambridge University Press.

Tavakol, Sina, Reg Dennick, and Mohsen Tavakol. 2011. Psychometric properties and confirmatory factor analysis of the Jefferson Scale of Physician Empathy. BMC Medical Education 11: 54.

van Mook, Walther N.K.A., Scheltus J. van Luijk, Willem de Grave, Helen O’Sullivan, Valerie Wass, Lambert W. Schuwirth, and Cees P.M. van der Vleuten. 2009. Teaching and learning professional behavior in practice. European Journal of Internal Medicine 20: e105-e111.

Vivanco, Luis and Roberto Delgado-Bolton. 2015. Professionalism. In Encyclopedia of Global Bioethics, ed. Henk Ten Have. Dordrecht: Springer Science+Business Media. doi:10.1007/978-3-319-05544-2_353-1

Wen, Deliang, Xiaodan Ma, Honghe Li, Zhifei Liu, Bensong Xian, and Liu Yang. 2013. Empathy in Chinese medical students: psychometric characteristics and differences by gender and year of medical education. BMC Medical Education 13: 130.

Wetzel, Angela P., Paul E. Mazmanian, Mohammadreza Hojat, Kathleen O. Kreutzer, Robert J. Carrico, Caroline Carr, Jon Veloski, and Azhar Rafiq. 2010. Measuring medical students' orientation toward lifelong learning: a psychometric evaluation. Academic Medicine 85: s41-s44. 